
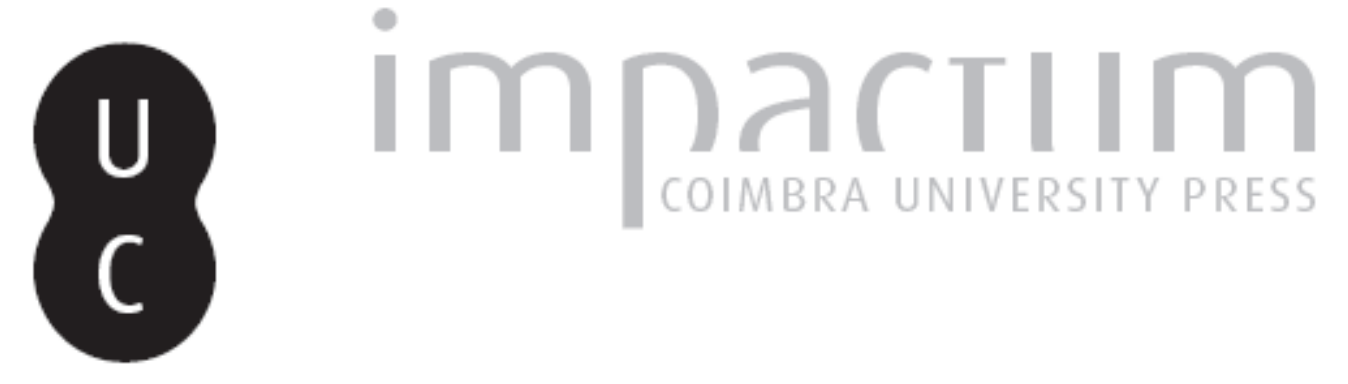

\title{
O código Lévi-Strauss ou o mundo como correlato objectivo
}
Autor(es):
Verde, Filipe
Publicado por: CIAS - Centro de Investigação em Antropologia e Saúde
URL persistente:
URI:http://hdl.handle.net/10316.2/28747
DOI:
DOI:http://dx.doi.org/10.14195/2182-7982_25_2
Accessed : $\quad$ 26-Apr-2023 13:33:08

A navegação consulta e descarregamento dos títulos inseridos nas Bibliotecas Digitais UC Digitalis, UC Pombalina e UC Impactum, pressupõem a aceitação plena e sem reservas dos Termos e Condições de Uso destas Bibliotecas Digitais, disponíveis em https://digitalis.uc.pt/pt-pt/termos.

Conforme exposto nos referidos Termos e Condições de Uso, o descarregamento de títulos de acesso restrito requer uma licença válida de autorização devendo o utilizador aceder ao(s) documento(s) a partir de um endereço de IP da instituição detentora da supramencionada licença.

Ao utilizador é apenas permitido o descarregamento para uso pessoal, pelo que o emprego do(s) título(s) descarregado(s) para outro fim, designadamente comercial, carece de autorização do respetivo autor ou editor da obra.

Na medida em que todas as obras da UC Digitalis se encontram protegidas pelo Código do Direito de Autor e Direitos Conexos e demais legislação aplicável, toda a cópia, parcial ou total, deste documento, nos casos em que é legalmente admitida, deverá conter ou fazer-se acompanhar por este aviso.

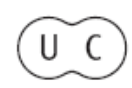




\section{Antropologia Portuguesa}

Volume $24-25 \cdot 2007-2008$

Departamento de Antropologia | Universidade de Coimbra

\section{Dossier Temático \\ CLAUDE LÉVI-STRAUSS}




\title{
O código Lévi-Strauss ou o mundo como correlato objectivo
}

\author{
Filipe Verde \\ Departamento de Antropologia \\ Instituto Superior de Ciências do Trabalho e da Empresa \\ Universidade de Lisboa \\ filipe.verde@iscte.pt
}

Resumo O propósito deste artigo é expor sinteticamente o essencial do conteúdo metodológico e filosófico do estruturalismo de Lévi-Strauss e sujeitá-lo a um julgamento crítico. O ponto de apoio a essa crítica é uma concepção de linguagem muito distinta da de Saussure - a inspiração da semiologia da cultura de LéviStrauss - que, entre outros méritos, permite mostrar o carácter ilusório das cisões ontológicas de que depende o método estrutural e os limites epistemológicos que lhes são inerentes.

Palavras-chave Estruturalismo; formalismo; lógica do sensível; arte; linguagem.

\begin{abstract}
The aim of this article is to expose and criticize the methodological and philosophical guidelines of Lévi-Strauss's structuralism. The support of such criticism is an idea of language quite different from Saussure's, a conception of language that, besides other merits, shows the illusory character of the ontological discontinuities in which the structural method depends upon and its epistemological limits.
\end{abstract}

Key words Structuralism; formalism; logics of sensible; art; language.

Quaisquer que venham a ser as precisões e modificações que devam ser feitas à fórmula, parece já adquirido que todo o mito (considerado como o conjunto das suas variantes) é redutível a uma relação canónica do tipo:

$$
\mathrm{F}_{x}(\mathrm{a}): \mathrm{F}_{y}(\mathrm{~b})=\mathrm{F}_{x}(\mathrm{~b}): \mathrm{F}_{a-1}(\mathrm{y})
$$

na qual, dois termos $a$ e $b$ sendo dados simultaneamente assim como duas funções $x$ e $y$, desses termos, colocam uma relação de equivalência entre as duas situações, definidas respectivamente por uma inversão dos termos e das relações, sob duas condições: $1^{\mathrm{a}}$ que um dos termos seja substituído pelo seu contrário (na expressão acima: $a$ e $a-1$ ); $2^{\text {a }}$ que uma inversão correlativa se produza entre o valor de função e o valor de termo dos dois elementos (acima: y e $a$ ) (Lévi-Strauss, 1958: 252-253). 
A estrutura laminada do mito (...) permite ver nele uma matriz de significações disposta em linhas e colunas, mas onde, de qualquer forma que a leiamos, cada plano reenvia sempre a um outro plano. Da mesma maneira, cada matriz de significações reenvia a uma outra matriz e cada mito a outros mitos. E se nos perguntarmos a que significado último reenviam estas significações que se significam umas às outras, mas que devem no fim de contas e em conjunto reportar-se a algo, a única resposta que este livro sugere é que os mitos significam o espírito, que os elabora por meio do mundo de que ele próprio é parte (Lévi-Strauss, 1964: 346).

Que linha de pensamento pode conduzir a tão singulares ideias? Basta conhecermos quem as assina para sabermos a resposta: o estruturalismo, ou seja, o movimento, escola ou acordo, que não chegou a ser nenhuma dessas coisas, sobre o uso a dar em domínios não linguísticos às ideias da linguística estrutural de Saussure, de que Lévi-Strauss foi o front runner. Num famoso cartoon, sentados numa praia tropical, com saias de folhas e em amena cavaqueira, estão com ele as outras três figuras maiores do estruturalismo: Foucault, historiador das ideias, Barthes, crítico literário, e Lacan, freudiano ultra-heterodoxo. Todos em algum momento se afirmaram desconfortáveis com o rótulo de estruturalista e com os usos relaxados a que a palavra foi sujeita e um deles chegou a recusar ter alguma vez sido tal coisa. Mas não se trata aqui de outra coisa do que do estruturalismo antropológico, tal como foi criado e desenvolvido por Lévi-Strauss, que com ele de alguma forma se confunde.

É de rigor começar qualquer discussão sobre o estruturalismo com Saussure. A descoberta saussuriana resume-se numa fórmula - a língua é forma e não substância. O que a define é o facto de poder ser descrita como um sistema de diferenças que não conhece senão a sua própria ordem. Tratava-se sempre para os seus cultores de afastar da ciência da linguagem o que lhes parecia ser obstáculo para alcançar o patamar de uma objectividade sem mácula, uma objectividade não sobre o real ou a consciência mas sobre a linguagem desligada e purificada das coisas que significa, como ordem puramente "significante". A partir de um número tanto mais limitado de unidades quanto mais descemos em direcção ao seu nível fonológico, ela produz-se como uma combinatória impecavelmente ordenada de elementos distintos. Percorrendo o caminho até às suas unidades mais elementares, aos seus "átomos", por assim dizer, o que se pretendeu encontrar foi o correlato 
do que a física pretendeu e pretende encontrar quando constrói os seus aceleradores de partículas - a física procura as leis fundamentais da matéria, a linguística as leis fundamentais dessa coisa sumamente e por definição imaterial que é a linguagem. A primeira luta ainda hoje para definir o seu "modelo standard", a segunda, através da fonologia, pensou ter encontrado o seu pelos anos 40 do século XX.

Penetrar os segredos da organização fonológica foi uma conquista proporcional às dificuldades do desafio que a guiava. Qualquer analfabeto sabe distinguir mesa e cadeira, subsumir céu em azul e opor bem e mal. Quando permanecemos no nível semântico é fácil e automático identificar unidades linguísticas, distingui-las, integrá-las em classes e gradações, porque as palavras são meio de outra coisa, o que elas esgrimem é o mundo, os seus objectos, ideias, qualidades e relações. Mas até aos trabalhos de Troubetzkoy e Jakobson ninguém na linguística tinha sabido ou sabia qualificar a relação entre, digamos, o som "a" e o som "i”, a não ser como de diferença não sistemática - "a" é diferente de "i" da mesma maneira que é diferente de todos os outros sons que o aparelho vocálico pode produzir. Nesse domínio em que a referência ao mundo deixa de contar, ou em que dele apenas retemos o que é "puro som", dir-se-ia, encontram-se os limites da linguagem, o limiar do terreno passível de ser descrito como tal. Mas, era este o incómodo da questão, a linguagem opera por meio de sons (ou mais precisamente "imagens acústicas"), e portanto os sons tinham de ser eles próprios passíveis de descrição linguística. O passo de génio de Jakobson foi o de, mais uma vez como na física, a procura de elucidar o "átomo" ter levado à descoberta de unidades mais elementares. Quarks ou gluões na física, "traços" ou "oposições distintivas" na linguística. Onde estava o fonema estavam agora um conjunto de relações passíveis de ser integradas numa matriz, onde "a" e "i", se opõem como grave e agudo, aberto e fechado, anterior e posterior, cujo quadro total de permutações permite aceder às leis lógico-estruturais (binárias) do sistema linguístico. Chegado aqui o programa saussuriano chegava ao seu terminus. Alcançado o nível onde os "valores" linguísticos (i.e. o lugar de um termo no conjunto geral de relações que mantém com os outros termos no quadro do todo) se definem independentemente do significado, a linguagem aparece como pura forma - como sistema que "não conhece senão a sua própria ordem".

A sedução do estruturalismo para os seus praticantes foram as suas promessas reducionistas - pelas quais o estruturalismo podia ser mais, 
muito mais, do que uma ciência da linguagem. Logo desde os seus primeiros passos, o reducionismo foi a direcção tomada pela linguística estrutural que cada vez com lentes mais fortes foi descendo até ao fonema e aos seus traços distintivos, o ponto em que a linguagem, como vimos, seria redutível a uma organização puramente lógica, onde tudo é sintaxe e nada é semântica. Mas esse era ainda um reducionismo que se travava dentro dos limites da língua. Seduzido pelas capacidades de formalização e pela natureza dedutiva da fonologia, Lévi-Strauss não crê que o método estrutural deva ficar circunscrito à linguística, e o que o estruturalismo propõe é uma extensão radical da sua área de competência. Afinal, a língua é apenas uma das dimensões da cultura, e porque não hão-de outras dimensões desta ser redutíveis a uma formalização semelhante? O método estrutural opera assim como uma "espécie de filtro que deixa passar o que podemos chamar de conteúdo lexicográfico das instituições e dos costumes, para apenas reter os seus elementos estruturais" (Lévi-Strauss, 1958: 30).

Tornando uma história longa numa história curta, o estruturalismo de Lévi-Strauss pode ser visto como fixando cada vez mais a sua atenção no que da cultura vai ficando retido num filtro cuja malha se vai cada vez mais apertando - o caminho que leva do parentesco ao "totemismo" e às classificações sensíveis e, finalmente, ao diamante que brilha mais do que qualquer outro objecto, o mito. Os extremos encontram-se: é ao nível mínimo (fonema-sistema fonológico) e máximo (mitema-sistema mitológico) da complexidade estrutural que encontramos "unidades desprovidas de significação, mas que permitem produzir significações num sistema onde se opõem entre elas e pelo facto de se oporem" (Lévi-Strauss, 1976: 16). O fonema e o mitema são portanto a estrutura no seu grau último de depuração, não são nem se referem a "coisas", nem estão assim contaminadas pela entropia que impera no mundo em que elas existem ou pela subjectividade dos seus utilizadores. O objectivo é o fechamento já não do campo fonológico mas do campo mítico, a descrição do último nível, dito "hiper-estrutural" (LéviStrauss, 1973: 169) da linguagem humana, que se sobrepõe em termos de complexidade aos outros, fonológico, morfológico e semântico.

Dir-se-ia que no culminar desse processo de redução o formalismo está ameaçadoramente perto. $\mathrm{O}$ formalismo nunca andou aliás longe do projecto estruturalista em linguística, tendo por vezes chegado a confundir-se com ele - são conhecidos os laços do chamado Círculo de Praga com a Escola formalista russa, de que Jakobson foi uma figura proeminente. 
Mas, felizmente para Lévi-Strauss, que não quer de todo ser confundido com o formalismo (ver Lévi-Strauss, 1973: 139-173), o mito está cheio de conteúdos. Ele é aliás voraz e omnívoro no que a conteúdos diz respeito, dado que o seu vocabulário, as suas "categorias", lhe são dadas pelo mundo concreto e pelas suas propriedades sensíveis - o cru e o cozinhado, o mel e o tabaco, a caça e a agricultura, os homens, os animais e plantas, do céu ao mundo subterrâneo todo o universo está lá dentro. Mas está lá dentro, atenção, enquanto organização lógica, como espelho de um "inconsciente categorial", meta-histórico e meta-societal, que se expressa em todos os produtos da actividade ordenadora da mente, sob a forma de uma lógica das qualidades sensíveis, indissociável do concreto e da percepção estética, mas também sob a forma dos modelos por vezes muito abstractos que a ciência produz.

Segundo Ricoeur, numa famosa definição filosófica sintética do estruturalismo, que Lévi-Strauss acolheu, estamos perante um "kantismo sem sujeito transcendental" (ver Ricoeur, 1965: 34; e Lévi-Strauss, 1964: 19). Mas se Kant separava rigorosamente mente e realidade, Lévi-Strauss torna-os uma só coisa, pois que o "espírito" e o "mundo" se encontram e tornam indistintos quando descobrimos as suas propriedades lógicas naturais comuns. No quadro de um pan-logicismo de proporções hegelianas, o estruturalismo metodológico converte-se assim numa filosofia (um idealismo materialista), uma filosofia necessária para que o método se afigure como algo mais do que um jogo gratuito. A verdade do método tem o seu "molde", e portanto a sua sanção última, numa identidade de natureza entre sujeito e objecto, pela qual o "espírito" é assimilado à "matéria", a mente e os seus produtos às condições "físico-químicas" do cérebro - e assim, se não foi Lévi-Strauss à objectividade, veio a objectividade a Lévi-Strauss...

É de facto muito problemática, como Ricoeur assinalou, a passagem de uma ciência estrutural a uma filosofia estrutural, na medida em que o método estrutural, contrariamente ao que Lévi-Strauss pretende, revelaria não tanto as condições a priori de todo o pensamento como as condições a priori do próprio método e dos postulados filosóficos que o sustentam i.e., do pensamento singularmente idiossincrático de Lévi-Strauss (Ricoeur, op.cit.). A passagem do estruturalismo metodológico a uma filosofia depende, em última instância, como mostra Eco num livro fundamental para situar o estruturalismo (Eco, 1991), do deslizar do nominalismo para o realismo, pelo qual um método ou conjunto de "procedimentos operacionais" se tornam o 
passaporte de uma dedução ontológica. Da ideia prudente segundo a qual é possível e eventualmente produtivo em termos heurísticos descrever e analisar a linguagem ou qualquer outra dimensão da cultura como se fosse uma estrutura, alguns linguistas deram quase naturalmente o passo reificatório em direcção a uma outra e muito diferente ideia, que afirma que ela é uma estrutura - a armadilha em que Lévi-Strauss também caiu quando pretendeu aceder através do mito nada mais nada menos do que às leis universais do "espírito humano", i.e. da própria Natureza.

Mas, posta de parte a troca do nominalismo pelo realismo, de uma modesta verdade de razão por uma metafísica verdade de facto, a capacidade heurística e o próprio estatuto de cientificidade do estruturalismo metodológico jogou-se dentro dos limites afinal estritos a que ele reduziu os seus objectos - e talvez esses objectos não sejam redutíveis ao que o estruturalismo os quis reduzir. A sensação que quase inevitavelmente assalta os leitores de Lévi-Strauss é a de vertigem e, rapidamente, de cansaço. Posto em acção o código Lévi-Strauss, dir-se-ia que nada o pode deter. Postulando que o pensamento selvagem e mitológico é de "um rigor meticuloso na aplicação prática de um esquema lógico" (Lévi-Strauss, 1962: 189), Lévi-Strauss procura demonstrá-lo por meios que rapidamente desconfiamos serem eles próprios muito pouco rigorosos. Mestre inultrapassável do uso da inversão simétrica, da sinédoque abstracta e da antítese (ver Sperber, 1985), dotado de uma imaginação poderosa e de uma capacidade única de ordenar esquematicamente a complexidade da informação etnográfica, na sua mão a mais remota semelhança ou contraste entre elementos - que não são aliás o mais das vezes senão meros pormenores dos objectos culturais em análise -, é pretexto de construções que muitas vezes se afiguram verdadeiramente fantásticas, mas que nos são apresentadas como a dimensão até então desconhecida desses objectos, a ordem inteligível e inconsciente que lhes é imanente. $\mathrm{Na}$ busca de proceder ao inventário das relações, elementos, códigos, permutações e transformações do sistema mítico, seguindo uma estratégia em que cada mito e grupo de mitos convida a integrar outros e outros e ainda outros mitos, no processo em que cada "matriz remete a outra matriz", numa deriva que encontra a sua expressão sintética na "fórmula canónica" mas que não parece por isso ter fim ou rumo, só o leitor mais estóico ou mais capaz de se deixar burlar pelo carácter vertiginoso do empreendimento consegue percorrer as quase 2000 páginas das Mythologiques... 
E no entanto, como se fosse preciso dizê-lo, a obra de Lévi-Strauss é uma obra clássica da antropologia, que marcou um tempo, um modo e um estilo de a praticar, é uma obra genial. Não fora o génio do seu autor, provavelmente a mais ninguém ocorreria sequer começar a percorrer os caminhos que Lévi-Strauss dir-se-ia percorreu até ao ponto mais distante, ou mesmo excessivo, a que ele conduz. O estruturalismo foi uma magnífica experiência antropológica, que incendiou polémicas, alargou enormemente os domínios da curiosidade etnográfica e acabou por contribuir, reactivamente, por apontar os caminhos futuros, mais interpretativos, politizados e radicalmente pós-objectivistas, da antropologia - gostar ou não gostar desses novos caminhos e julgar os méritos de os percorrer ou não percorrer é outra coisa, porque entretanto já se virou uma página da história da disciplina.

Entre os seus estudos sobre o parentesco e o virar-se definitivamente para a mitologia, Lévi-Strauss publicou um livro, La pensée sauvage, que sem dúvida está a par, no panteão dos textos clássicos da antropologia, de Primitive culture, Argonauts of the western Pacific e The interpretation of cultures. É certo que essa é sem dúvida a obra em que o estruturalismo de forma mais desmedida explora a estratégia metodológica que o define e que acima considerámos criticamente, mas o livro é muito mais do que um exercício de virtuosismo estruturalista. Trata-se nada mais nada menos do que procurar caracterizar o conhecimento que resulta de um pensamento ainda não "domesticado", i.e., que não se guia por noções como "causa", "história", "sujeito" ou "certeza", que não dispõe da escrita e do cálculo, de microscópios ou telescópios, de instrumentos ou unidades de medida, e que se ergue todo ele a partir dos dados da sensibilidade. O pensamento em "estado selvagem" não é porém intelectualmente desinteressado ou mera e limitadamente orientado pelas necessidades do estômago. Ele resulta não da sede e da fome, mas da vontade irreprimível de conhecer ou, como diz Lévi-Strauss, de uma "necessidade de ordem", de apreender o mundo como dotado de significado ou, ideia talvez mais fiel ao espírito da obra, como matéria-prima para tal. A riqueza, complexidade e exaustividade das taxinomias "primitivas" são a ilustração por excelência de que uma "ciência" está aí presente, uma "ciência do concreto" que "explora o mundo sensível em termos de sensível", cuja importância histórica é iniludível dado que imperou sozinha desde o neolítico até ao advento da ciência moderna, e cujas estratégias e resultados são sob muitas perspectivas comparáveis aos desta última. E é justamente nas páginas em que caracteriza o pensa- 
mento selvagem ou mítico e a ciência do concreto, e precisamente para os caracterizar, que Lévi-Strauss cria algo que, tanto ou mais do que os seus princípios metodológicos explícitos, define uma obra e o seu sentido: as suas metáforas centrais.

E as metáforas do estruturalismo são o bricolage e o caleidoscópio. Combinando de modo livre um material sensível heteróclito que resulta de processos e encontros contingentes, o bricoleur constrói objectos que não expressam senão a sua sujeição a princípios estritos de necessidade. $\mathrm{O}$ bricoleur agita o caleidoscópio que a cada movimento recombina os seus conteúdos e através de um jogo invariante de espelhos produz de cada uma dessas vezes uma possibilidade de um padrão último e sintético que é a impressão digital do "Espírito Humano". Para o Lévi-Strauss filósofo, i.e. que procura numa opção filosófica a fundamentação e sanção de um método, o pensamento e o mundo são, digamos assim, correlatos objectivos - o mundo é o pensamento objectivado e o pensamento o mundo subjectivado. E como o pensamento é, di-lo o reducionismo que vem da linguística, forma, a natureza é ela própria forma, ou melhor, o conteúdo que preenche uma forma porque já ele próprio Forma... Desse modo procura-se reunir por meio de uma filosofia o que o método antes dividiu, e que talvez não tenha ou deva sequer ser dividido.

O que o estruturalismo começou por dividir foi as palavras das coisas, a linguagem do mundo. Para Saussure tratava-se primeiro que tudo de afirmar a separação ontológica entre o mundo e as suas entidades, por um lado, e as palavras que as designam, por outro, entre o "referente" e o "signo". Tratava-se em segundo lugar, no interior do signo, de separar o significante (a imagem acústica, a sequência sonora "leão", por exemplo), do significado (a ideia ou conceito de leão), definindo a sua relação como arbitrária ou convencional (dado que, em línguas diferentes, a ideia de leão está associada a significantes diferentes: "leão", "lion", "löwe"...), e compreender todo o signo a partir dessa característica. Tratava-se afinal de prolongar o projecto moderno de fragmentar o logos grego e de tornar a linguagem um domínio próprio, definindo-a como um "sistema de signos", como uma estrutura autónoma e não referencial de significação, cujas "unidades" são "valores", dado que o seu sentido é apenas "negativo" e "posicional", i.e., função da sua "diferença" em relação aos outros signos no quadro global do sistema. 
A objectividade perseguida pelo estruturalismo baseou-se assim na concepção ou postulado prévio de que a relação entre o mundo e a linguagem é contingente, que cada um deles se define independentemente do outro, que as suas esferas de inteligibilidade são distintas e autónomas. Dir-se-ia que podíamos estar a descrever o formalismo matemático e a sua natureza puramente "ideal" e auto-referencial, e de certo modo trata-se disso mesmo, de uma matematização da linguagem e, com Lévi-Strauss, do que na cultura é homólogo à linguagem ou é a sua expressão "hiper-estrutural" - e assim Hjelmslev procurava "um cálculo exaustivo e geral das combinações possíveis" (Hjelmslev, 1969: 9) que constituem a linguagem, e Lévi-Strauss chega à conclusão que o mito é "redutível a uma relação canónica do tipo: $\mathrm{F}_{x}(\mathrm{a}): \mathrm{F}_{y}(\mathrm{~b})=\mathrm{F}_{x}(\mathrm{~b}): \mathrm{F}_{a-1}(\mathrm{y})$ ”... Já sabemos que o formalismo está sempre muito próximo do estruturalismo, e que às vezes não se sabe como distingui-los.

Mas o modo de ser da linguagem não supõe, nunca supôs, essas divisões. Como o reconhece Benveniste, uma figura maior do estruturalismo, "para o falante há, entre língua e realidade, uma completa equivalência: o signo encobre e comanda a realidade; ele é essa realidade (...). Na verdade o prisma do sujeito e do linguista são tão diferentes a esse respeito que a afirmação do linguista quanto ao arbitrário das designações não refuta o sentimento contrário do falante" (Benveniste, 1988: 57). Talvez que a teimosia do falante e o senso comum linguístico que o informam nessa teimosia sejam em si mesmos bons motivos para tomarmos algum recuo em relação à ideia de que a arbitrariedade é a marca definidora de todo o signo, de que há uma cesura ontológica entre o mundo e as palavras, que devamos ver a linguagem como expressão e instrumento de um sujeito mental impessoal - para Lévi-Strauss do homo distinguens et discernens, que, movido por uma "necessidade de ordem", aplica ao real uma grelha que o classifica exaustivamente, organizando-o "vertical" e hierarquicamente do concreto para o abstracto, do particular para o geral, à luz de princípios estritos de inclusão e exclusão, como nos propõe a visão que desenvolve do pensamento selvagem.

Saussure estava no entanto bem consciente quanto a linguagem escapa à arbitrariedade, o quanto ela é simbólica, tributária da alusão, da analogia e da metáfora, de tudo, dir-se-ia, o que acontece for a da linguagem como sistema ou como estrutura lógica. Mas o seu reconhecimento de que há na linguagem dimensões não arbitrárias, não foi senão o passo prévio da afirmação da sua 
irrelevância para a linguística estrutural. O "símbolo" ficava assim fora da linguística do "signo", entregue às disciplinas que desde sempre lhe deram um lugar de destaque: a teologia, a retórica, a estética e a filologia. E o que é o símbolo? Sinteticamente, é símbolo o que no mundo e em função das suas características se apresenta como correlato objectivo de disposições e sentimentos, de ideias e pensamentos, e que, em função disso, se pode tornar o veículo ou expressão "sensível" destas. Qualquer sequência de sons pode ser associada à ideia de leão, mas o leão ele próprio só pode ser associado a algumas ideias - ele pode simbolizar a coragem e a força física, mas não a cobardia ou a fraqueza, porque o leão é aquilo que significa. Ou seja, o símbolo é o plano da linguagem em que, usando o jargão estruturalista, significante e significado estão ligados por uma relação de motivação, por um laço natural e não convencional, em que a palavra se apresenta mais como uma imagem do mundo do que como um signo caracterizado pela pura convencionalidade. Mas, tão rapidamente quanto Saussure afastou da sua concepção de linguagem as dimensões simbólicas desta, Lévi-Strauss afastou do lugar que iniludivelmente o sensível ocupa no pensamento selvagem e no mito tudo o que não se reporte à sua dimensão lógica ou estrutural - afinal esse sensível é tornado parte destes porque se apresenta como uma "lógica do sensível", porque se encontra objectivamente dado como "sistema de diferenças", e portanto como "código", na própria natureza.

Sendo possível distinguir signo e símbolo, significante e significado, a linguagem e o mundo, não temos por isso que acreditar que as fronteiras que assim traçamos sejam mais do que, como diria Eco, "ficções operacionais". Distinções que não correspondem afinal a diferenças, aquilo para que servem parece ser primordialmente para ilustrar quanto a complexidade da linguagem humana é resistente a deixar-se aprisionar por elas. Nem puramente sígnica (porque não há maneira de dissociar as palavras das coisas sem esvaziar artificialmente a linguagem da sua função cognitiva), nem puramente simbólica (dado que o símbolo significa sempre mais do que o que é fisicamente, e esse mais depende do seu enraizamento cultural), mas talvez mais simbólica do que sígnica, a linguagem é, como o revela globalmente a história da filosofia do século XX e os próprios desenvolvimentos teóricos da ciência linguística (ver Lucchesi, 1998), outra coisa e muito mais do que aquilo que a linguística estrutural e o estruturalismo quiseram que ela fosse. 
É no quadro das suas episódicas mas frequentes reflexões sobre a arte e a estética que encontramos na obra de Lévi-Strauss um distanciamento das cisões ontológicas que suportam o estruturalismo e um vislumbre do amplo território que está para além delas. Sem dúvida que essas reflexões trazem as marcas da perspectiva estrutural, e desde logo no que se refere à ideia de que arte não se define per se, mas apenas como termo de um quadro de semelhanças e contrastes com outras actividades humanas, como a ciência e o mito. $\mathrm{O}$ que distinguiria aliás e fundamentalmente a arte da ciência seria o facto de, diferentemente desta que opera através de conceitos, a arte operar através de signos. Mas também aí o que está em jogo é instaurar um princípio de ordem sobre a contingência e o carácter heteróclito dos elementos do mundo, e quem joga esse jogo é tanto um savant quanto um bricoleur - a arte define-se portanto como estando "a meio caminho entre o conhecimento científico e o pensamento mítico ou mágico" (Lévi-Strauss, 1962: 33) A partir das premissas estruturalistas esperar-se-ia que Lévi-Strauss fosse inevitavelmente conduzido a alguma forma de diferenciação estética, pela qual a consciência estética do produtor e do receptor da arte são separadas dos seus mundos respectivos, que se procurasse a arte como arte, que a atenção à substância e sentido da arte fosse sacrificada ao juízo estético "puro" e à descrição das propriedades estruturais e transformacionais de um sistema cujas unidades seriam os "artemas". Mas o facto de a arte, reconhecidamente, ser não apenas uma forma de produção de sentido mas também de conhecimento, afastou a possibilidade de a "estética de Lévi-Strauss" se deixar aprisionar pelo artificialismo das cisões saussurianas.

Se o caminho seguido não foi esse é talvez porque na arte é iniludível que estamos perante algo mais do que signos. A pintura de Clouet que LéviStrauss evoca em La pensée sauvage para definir a arte a partir da ideia de "modelo reduzido", por exemplo, é "mais" e outra coisa que um signo - é o retrato de Elisabete da Áustria, uma sua representação feita à luz de um desígnio de semelhança e correspondência em relação ao seu modelo. Daí que para Lévi-Strauss, e na sua terminologia, a arte seja "um sistema de significação" que está a "meio caminho entre a linguagem e o objecto" (Lévi-Strauss in Charbonnier, 1959: 131), dado que "a obra de arte, ao significar o objecto, consegue elaborar uma estrutura de significação que tem uma relação com a estrutura do próprio objecto" (ibid.: 108-109). Numa palavra, a obra de arte é mimética, toma o mundo como objecto e, desse modo, revela o próprio mundo, ela tem portanto um valor cognitivo, sendo 
uma forma já não tanto de produção de sentido mas de conhecimento. A ideia de mimesis que guia Lévi-Strauss é inevitavelmente muito diferente da que guiou a estética clássica e que a crítica impiedosa do romantismo reduziu a cacos, dado que a obra de arte, por mimética que seja, não é jamais uma réplica, cópia ou transcrição literal do mundo. A arte é mimética e por isso é meio de conhecimento, mas é-o porque ela não se limita, acaso fosse isso possível, a imitar o mundo, mas porque pelo contrário o secciona, simplifica, lhe muda os ênfases e em certo sentido o "fecha" no interior de cada obra, subtraindo-o assim ao que lhe é inessencial e contingente e revelando-o em termos como nunca antes se havia revelado. Como diz em La pensée sauvage, o "tipo mesmo de obra de arte" (como o ilustra o retrato de Clouet), é o "modelo reduzido", e aquilo a que acedemos através da arte é a uma "transposição quantitativa" simplificadora (Lévi-Strauss, 1962: 35) do que ela representa. Dessa forma, a arte opera "verdadeiras experiências sobre os objectos", dando-os a conhecer de uma forma que só a arte é capaz.

Nesse passo, e apesar da vertigem matematizante que guia Lévi-Strauss, ficamos muito distantes de Saussure e do equívoco que move as concepções formais da linguagem - talvez porque a ideia que convém mais a uma compreensão da linguagem não seja a de signo, nem mesmo a de símbolo, mas antes a de imagem, o que torna a pintura de Clouet interessante de uma outra forma.

O "sentido" do quadro de Clouet é o que ele dá a ver ou mostra, o que torna presente ou, nos termos de N. Goodman (1984) em Languages of art, o que denota - é o retrato de uma aristocrata do século XVI, Elisabete da Áustria, filha do sacro imperador germânico Maximiano II e de Maria de Espanha, que casou com Carlos IX de França. Mas a um segundo olhar sabemos que não se trata apenas disso, dado que sendo uma pintura, aquilo que ela mostra, mostra como representação. Não é o modelo que temos perante nós mas o modo como Clouet o captou, não o original mas uma sua imagem, e a pintura tem portanto existência autónoma em relação ao que representa. O que nos dá a ver não é algo que pudéssemos ver independentemente dela e trata-se, sim, de Elisabete da Áustria, mas tal como presente na pintura e não Elisabete da Áustria ela mesma. Mas, a um terceiro momento da nossa observação do quadro de Clouet, o que nos é dado a compreender é que essa dualidade é afinal ilusória, porque imagem e modelo são inseparáveis um do outro. Para o observador, original e imagem em certo sentido pertencem-se, dado que uma vez conhecida a pintura o que quer que possa conceber como "original" é forçosamente concebido à luz do modo como ela o apresenta. 
Tal como a imagem, a palavra não é a coisa porque está dela dividida e separada, mas tal como a imagem a palavra é, digamos, uma emanação ou manifestação da coisa, algo que dela não pode ser separado porque afinal palavra e coisa, como o afirma o senso comum do utilizador da linguagem, pertencem-se. A palavra é assim o que simultaneamente divide e dá unidade ao que dividiu - como diz Gadamer "tudo o que é linguagem tem uma unidade especulativa: ela contém uma distinção entre o ser e o modo como ele se apresenta, mas essa distinção na realidade não é de todo uma distinção" (Gadamer, 1989: 475). Nos termos da filosofia hermenêutica a pintura-imagem é o modelo mesmo da linguagem como o "Ser que pode ser compreendido", como "meio pelo qual e através do qual nós existimos e compreendemos o nosso mundo" (Gadamer, 1977: 29). Nesse sentido, a linguagem assemelha-se à luz como aquilo que torna as coisas visíveis - uma imagem de Tomás de Aquino que a filosofia hermenêutica retomou e que revela, e como imagem mostra, o quanto as palavras "aprofundam" aquilo que procuram descrever e compreender e o quanto portanto elas "completam e complementam" a inteligibilidade do mundo (ibid.: 447).

Sperber, num livro já antigo, diz que o simbolismo é uma "fonte de luz" que não deve ser olhada, porque quem o faz logo fica encandeado e diz "não vejo nada", dado que "a luz está lá não para ser olhada mas para que possamos ver o que ela ilumina" (Sperber, 1974:70). O mesmo se pode dizer genericamente da linguagem, dado que o seu modo de ser quando não se converte em metalinguagem e serve a sua vocação cognitiva e representacional (i.e., aquela que é sempre a sua vocação, excepção feita aos devaneios formalistas), é ser invisível perante a realidade que traz para dentro de si e torna pensável, no passo em que ela própria deixa de o ser. É que nem luz nem linguagem são algo que possamos ver senão através do que iluminam. Elas estão lá não para ser olhadas como coisas em si mesmas mas para mostrar o mundo, para o tornar presente e interpretável - dando-lhe cor e nitidez, complementando e completando a sua inteligibilidade. Tivesse Lévi-Strauss olhado menos para a luz e mais para o que ela ilumina, trazido para o pensamento selvagem e para o mito o que reservou para a arte, buscado não o plano "hiper-estrutural" da linguagem mas a linguagem na sua dimensão terrena, talvez a sua mensagem tivesse sido menos monótona - como sabemos, no fim do caminho estruturalista o que nos espera é inevitavelmente a cesura ontológica entre as palavras e o mundo e a monotonia do espírito "frente a frente consigo mesmo" e a significar-se a si mesmo. 
"O mito da mitologia", é assim que Lévi-Strauss define as Mythologiques logo na sua "Abertura". Para além do código linguístico e dos códigos pelos quais o mito se elabora compondo e recompondo os dados da sensibilidade como objectos num caleidoscópio, estaria um "código de terceira ordem" - uma espécie de Ur-código, a chave dos segredos do próprio caleidoscópio, o Graal da mente como estrutura lógica. Depois e sobrepondo-se aos sistemas fonológico e da língua (códigos de primeira ordem) está o sistema mítico (de segunda ordem); para além do sistema mítico, sobrepondo-se a ele, integrando-o e reduzindo-o às derivações da fórmula canónica, estão as Mythologiques, a obra que ao "assegurar a traduzibilidade recíproca de muitos mitos" é esse "código de terceira ordem". Encerrado nas suas páginas, o único nome possível para ele que não esse é o nome do autor que as assina: Lévi-Strauss, o código Lévi-Strauss. Construção absolutamente idiossincrática, que não poderia ter saído da cabeça de mais ninguém senão de Lévi-Strauss, o estruturalismo antropológico (que em certo sentido com ele se confunde e a ele se resume) é a manifestação do que os românticos chamavam de "génio", aquele que através de uma visão íntima e em última análise incomunicável produz as obras nas quais o mundo é iluminado de uma forma própria, tão própria que no-lo revela em termos que de outro modo nunca chegaríamos a ver. A "meio caminho" entre o mito e a ciência, porque se trata de fazer uma ciência da mitologia, as Mythologiques não podem ser então outra coisa senão uma obra de arte, "o mito da mitologia", que está aí para nos lembrar, como se isso fosse necessário, que a mitologia continua como desde sempre aí, a olhar para nós e a interpelar-nos - a iluminar-nos e ao mundo.

\section{Bibliografia}

Benveniste, É. 1988 (1966). Problemas de linguística geral 1. Campinas, Pontes Editores.

Charbonnier, G. 1961. Entretiens avec Claude Lévi-Strauss. Paris, Plon.

Eco, U. 1991 (1968). A estrutura ausente: Introdução à pesquisa semiológica. São Paulo, Editora Perspectiva.

Gadamer, H-G. 1989 (1961). Truth and method. London, Sheed \& Ward, $2^{\mathrm{a}}$ edição inglesa, revista e traduzida por Joel Weinsheimer e Donald G. Marshall.

Gadamer, H-G. 1977 (1976). Philosophical hermeneutics. Berkeley, University of California Press. 
Goodman, N. 1984 (1976). Languages of art. An approach to a theory of symbols. Indianapolis, Hackett Publishing Comapany.

Hjelmslev, L. 1969 (1953). Prolegomena to a theory of language. Madison, University of Wisconsin Press.

Lévi-Strauss, C. 1958. Anthopologie structurale. Paris, Librairie Plon.

Lévi-Strauss, C. 1962. La pensée sauvage. Paris, Librairie Plon.

Lévi-Strauss, C. 1964. Mythologiques I. Le cru et le cuit. Paris, Librairie Plon.

Lévi-Strauss, C. 1971. Mythologiques IV. L'homme nu. Paris, Librairie Plon.

Lévi-Strauss, C. 1973. Anthropologie structurale deux. Paris, Librairie Plon.

Lévi-Strauss, C. 1976. Préface. In: Jakobson, R. 1942-3. Six leçons sur le son et le sens. Paris, Les Éditions de Minuit.

Lucchesi, D. 1998. Sistema, mudança e linguagem: um percurso da linguística este século. Lisboa, Edições Colibri.

Ricoeur, P. 1965. O conflito das interpretações. Porto, Rés Editora.

Sperber, D. 1974. Le symbolisme en générale. Paris, Herman.

Sperber, D. 1985 (1982). On anthropological knowledge. Cambridge, Cambridge University Press.

Artigo recebido a 11 de Agosto de 2008 e aceite em 17 de Setembro de 2008. 